\title{
Analysis of the genotypes and phenotypes of 37 unrelated patients with inherited factor VII deficiency
}

\author{
Muriel Giansily-Blaizot ${ }^{*, 1}$, Patricia Aguilar-Martinez ${ }^{1}$, Christine Biron-Andreani ${ }^{1}$, \\ Philippe Jeanjean ${ }^{1}$, Hélène Igual ${ }^{1}$, Jean-François Schved ${ }^{1}$ and The Study Group of Factor \\ Seven Deficiency ${ }^{2}$
}

\author{
${ }^{1}$ Laboratory of Haematology, CHU Montpellier, University Hospital, Montpellier, France
}

Severe inherited factor VII (FVII) deficiency is a rare autosomal recessive disorder with a poor relationship between FVII coagulant activity and bleeding tendency. Both clinical expression and mutational spectrum are highly variable. We have screened for mutations the FVII gene of 37 unrelated patients with a FVII coagulant activity less than $5 \%$ of normal pooled plasmas. The nine exons with boundaries and the $5^{\prime}$ flanking region of the FVII gene were explored using a combination of denaturing gradient gel electrophoresis and direct DNA sequencing. This strategy allowed us to characterise 68 out of the 74 predicted FVII mutated alleles. They corresponded to a large panel of $\mathbf{4 0}$ different mutations. Among these, 18 were not already reported. Genotypes of the severely affected patients comprised, on both alleles, deleterious mutations which appeared to be related to a total absence of activated FVII. We suggest that this absence of functional FVII can explain the severe clinical expression. Whether a small release of FVII is sufficient to initiate the coagulation cascade and to prevent the expression of a severe phenotype, requires further investigations. European Journal of Human Genetics (2001) 9, 105-112.

Keywords: factor VII deficiency; haemorrhagic disorder; single base-pair mutation

\section{Introduction}

Human coagulation factor VII (FVII) is a vitamin-K-dependent glycoprotein that consists of a 406 amino-acid modular protein with a N-terminal-gamma-carboxyglutamic acid rich (Gla) domain, two epidermal growth factor-like (EGF)

\footnotetext{
*Correspondence: M Giansily-Blaizot, Laboratory of Haematology, CHU Montpellier, 80 avenue Augustin Fliche, 34295 Montpellier Cedex 5, France. Tel: +33 4673370 33; Fax: +334673370 36;

E-mail: m-giansily@chu-montpellier.fr

${ }^{2}$ The study group of factor seven deficency includes: MA Bertrand CHU Besançon, Dr JY Borg CHU Rouen, Dr ME Briquel CHU Nancy, Dr H Chambost CHU Marseille, Dr F Dutrillaux CHU Dijon, Dr R Favier AP-HP Paris, Dr V Gay Dr D Raffenot CHG Chambery, Pr J Goudemand CHU Lille, Dr R Navarro CHU Montpellier, Dr C Negrier Dr A Durin CHU Lyon, Dr R d'Oiron CTH Bicêtre Paris, Dr A Parquet Gernez ETS Lille, Dr G Pernod CHU Grenoble, Dr J Peynet Dr B Bastenaire CTH Le Chenay Paris, Pr P Sie CHU Toulouse, Dr N Stieltjes CTH Cochin Paris, Dr MF Torchet Dr C Gazengel ETS AP-HP Paris (France), Pr P de Moerloose CHU Geneve (Switzerland).

Received 11 July 2000; revised 22 September 2000; accepted 29 September 2000
}

domains and a C-terminal serine proteinase domain. After cleavage of an Arg-Ile peptide bond at residues 152/153, FVII is converted to the active form, factor VIIa (FVIIa) comprising two chains connected by a disulphide bridge between Cys 135 and Cys 262. FVIIa on its own has virtually no catalytic activity but triggers the coagulation at sites of injury by binding to the cell surface receptor tissue factor (TF) in the presence of calcium ions, ultimately resulting in thrombin generation and the formation of a fibrin clot. ${ }^{1}$

Inherited FVII deficiency is a rare autosomal recessive disorder with an estimated incidence of 1 in 500000 . The bleeding tendency in affected patients is highly variable and correlates poorly with plasma FVII activity levels. ${ }^{2}$ The clinical features vary considerably, from easy bruising, epistaxis, modest or severe postoperative bleeding, to lifethreatening intracranial haemorrhages. ${ }^{1-3}$ On the other hand, several asymptomatic patients with a FVII coagulant activity level less than $1 \%$ of normal have been reported. ${ }^{1}$ In addition, up to 70 different mutations underlying the FVII deficiency phenotype have already been described in the 
human FVII mutation database (http://europium.csc.mrc. ac.uk/usr). Study of the heterogeneous molecular basis of FVII deficiency offers the opportunity to investigate the mechanisms through which genotype is able to modulate the residual FVII activity and to produce a large spectrum of clinical phenotypes. For this purpose, we have collected clinical features and characterised the FVII genotypes of a large cohort of patients displaying FVII coagulant activity less than $5 \%$ of normal pool plasmas. This study is one of the largest ever reported on severe FVII deficiency. ${ }^{4-6}$

\section{Materials and methods Patients}

The panel consisted of 37 unrelated patients ( 22 females and 15 males) with inherited FVII deficiency attending 16 French centres specialising in the follow-up of haemorrhagic disorders. Patients who entered the study were selected on the basis of a factor VII coagulant activity level less than 5\% of normal (Table 1). All patients gave written informed consent in accordance with the French law. A family history of consanguinity was known for six patients.

\section{Clinical and biological data}

Clinical features were recorded by the physician in charge of each patient in a standardised questionnaire. Collected data focused on the diagnostic circumstances and on the bleeding tendency. The type, severity and frequency of the haemorrhagic symptoms were noted. The FVII coagulant activity (FVIIc) was assayed in each centre by a one-stage method based on the prothrombin time using thromboplastin reagents and FVII deficient plasma as a substrate. Factor VII antigen (FVIIAg) was determined using the Asserachrom FVII:Ag Kit (Diagnostica Stago, Asniere, France) according to the manufacturer's instructions (Table 1).

\section{Blood collection}

Blood samples were obtained from the 16 centres and mailed to the laboratory at room temperature within $24 \mathrm{~h}$, for DNA extraction.

\section{DNA isolation and conditions for polymerase chain reaction}

Genomic DNA was isolated according to standard methods. The coding portions, intron/exon boundaries and the $5^{\prime}$ flanking region ( $5^{\prime} \mathrm{FR}$ ) of the FVII gene were amplified from genomic DNA by polymerase chain reaction (PCR). Primer sets were designed according to the published FVII gene sequence $^{7}$ and are listed in Table 2 .

\section{Mutation detection by denaturing gradient gel electrophoresis (DGGE)}

DGGE was used to screen for sequence alterations, PCR fragments containing the portions of interest of FVII gene. MELT 87 and SQHTX computer programs, ${ }^{8}$ which allow simulation of the melting behaviour of any DNA sequence, were used to optimise the DGGE conditions. To ensure that the DNA portion of interest was within the lowest melting temperature domain, a GC rich region was added at one end of the fragment to be screened as described. ${ }^{8}$ As the melting map of exons 1a, 2, 3, 4, 6 and 7 did not easily allow the use of DGGE, these PCR fragments were directly sequenced. DGGE was performed for the mutation screening of exons $1 \mathrm{~b}, 5$ and 8 . Three sets of primers were used to independently amplify the three melting domains of exon 8 , generating fragments $8 \mathrm{~A}, 8 \mathrm{~B}$ and $8 \mathrm{C}$. Migration gels consisted of $6.5 \%$ acrylamide in a linear 50-90\% denaturing gradient and were run as previously described ${ }^{9}$ (Table 2). Samples displaying abnormal DGGE profiles were sequenced.

\section{Mutation detection by direct sequencing}

PCR amplified fragments for coding regions $1 \mathrm{a}, 2,3,4,6,7$, exon-intron boundaries, 5'FR and samples with an abnormal DGGE pattern were directly sequenced using the Big dye Terminator sequencing kit (Perkin Elmer, Norwalk, CT, USA) on an Applied 310 sequencing apparatus (PE, Applied Biosystems, Warrington, UK).

\section{Mutation screening strategy}

In this study, we have made an exhaustive genetic analysis of all FVII regions of interest so as not to miss doublemutations or polymorphisms that could be involved in the phenotypic variability. For each patient, the sequences of the nine exons and corresponding boundaries of FVII gene were analysed. Each nucleotide sequence alteration was confirmed on at least two independent PCR products by either restriction enzyme digestion, when the mutation modified a restriction site, or another independent sequencing analysis. If no mutation was found after the first screening-step, exons $1 \mathrm{~b}, 5$ and 8 were tested for heteroduplex formation under the same DGGE conditions, and the 5'FR was sequenced. If one or two mutations were still missing, exons $1 \mathrm{~b}, 5$ and 8 were then entirely sequenced.

\section{Results}

\section{Clinical and biological phenotypes}

The 37 patients investigated in this study were classified into three clinical groups (Table 1). Group A comprised asymptomatic patients with no bleeding history $(n=15)$. Group B included patients who experienced menorrhagia, epistaxis or bruising with no need for substitutive therapy $(n=13)$. Group C comprised patients with a history of severe bleeding (haematoma, haemarthrosis, intracranial haemorrhages) $(n=9)$. The severe disease group comprised only females, whereas the mild disease groups included 15 males and 13 females. No thromboembolic episode was related. 
Table 1 Identified phenotypes and genotypes of the 37 FVII deficient patients

\begin{tabular}{|c|c|c|c|c|c|c|c|c|}
\hline \multirow[b]{2}{*}{ Lab number } & \multirow[b]{2}{*}{$\operatorname{Sex}$} & \multirow{2}{*}{$\begin{array}{l}\text { Non French } \\
\text { origin }\end{array}$} & \multirow{2}{*}{$\begin{array}{l}\text { Clinical } \\
\text { group }\end{array}$} & \multicolumn{2}{|c|}{ Biological phenotypes (\%) } & \multicolumn{3}{|c|}{ Genotypes and haplotypes } \\
\hline & & & & FVII C & $F V I I A g$ & Allele 1 & Allele 2 & FVII haplotypes \\
\hline F7-11 & $\mathrm{F}$ & & A & $<1$ & 64 & Gly331 $\rightarrow$ Ser & Gln100 $\rightarrow$ Arg & (A1 H1 h6 I1 M1) X2 \\
\hline F7-16 & M & N Afr & A & $<5^{\mathrm{a}}$ & 25 & Ala191 $\rightarrow$ Thr & Ala191 $\rightarrow$ Thr & (A1 H1 h6 I1 M1) X2 \\
\hline F7-24 & M & N Afr & A & $5^{\mathrm{a}}$ & 44 & Arg304 $\rightarrow$ Gln & Ala244 $\rightarrow$ Val & $\mathrm{A} 1 \mathrm{~A} 1 \mathrm{H} 1 \mathrm{H} 1 \mathrm{~h} 6 \mathrm{~h} 7 \mathrm{I} 112 \mathrm{M} 1 \mathrm{M} 2$ \\
\hline F7-34 & $\mathrm{F}$ & & $A$ & $<5^{\mathrm{a}}$ & 55 & Arg304 $\rightarrow$ Gln & Cys135 $\rightarrow$ Arg & A1A1 H1H1 h6h7 I1/1 M1M1 \\
\hline F7-39 & $\mathrm{M}$ & & A & $3^{\mathrm{a}}$ & 10 & Ala244 $\rightarrow$ Val & Gly $179 \rightarrow$ Arg & $\mathrm{A} 2 \mathrm{~A} 2 \mathrm{H} 1 \mathrm{H} 2 \mathrm{~h} 7 \mathrm{~h} 7 \mathrm{I} 2 \mathrm{I} 2 \mathrm{M} 2 \mathrm{M} 2$ \\
\hline F7-33 & $\mathrm{F}$ & & A & $<1$ & na & 10543 del gcgagcacgacctca & Cys $310 \rightarrow$ Phe & (A1 H1 h6 I1 M1) X2 \\
\hline F7-38 & $\mathrm{F}$ & & A & $<5^{\mathrm{a}}$ & na & Arg304 $\rightarrow$ Gln & Arg304 $\rightarrow$ Gln & (A1 H1 h7 I1 M1) X2 \\
\hline F7-40 & $\mathrm{M}$ & & A & $<1^{a}$ & na & Cys $310 \rightarrow$ Phe & Cys310 $\rightarrow$ Phe & (A1 H1 h6 I1 M1) X2 \\
\hline F7-17 & $\mathrm{M}$ & $\mathrm{N}$ Afr & $A$ & & 37 & Met298 $\rightarrow$ lle & wt & A1A1 H1H1 h6h7 I1I1 M1M1 \\
\hline F7-31 & $\mathrm{F}$ & & A & 2 & 19 & Cys $102 \rightarrow$ Tyr & wt & $\mathrm{A} 1 \mathrm{~A} 1 \mathrm{H} 1 \mathrm{H} 1 \mathrm{~h} 6 \mathrm{~h} 7 \mathrm{I} 111 \mathrm{M} 1 \mathrm{M} 1$ \\
\hline F7-37 & M & A & & $5^{\mathrm{a}}$ & 7 & Ala244 $\rightarrow$ Val & wt & $(\mathrm{A} 1 \mathrm{H} 2 \mathrm{~h} 7 \mathrm{I} 2 \mathrm{M} 2) \times 2$ \\
\hline F7-15 & $M$ & N Afr & A & 1 & $<2$ & wt & wt & $(\mathrm{A} 1 \mathrm{H} 1 \mathrm{~h} 7 \mathrm{I1} \mathrm{M} 1) \times 2$ \\
\hline F7-1 & M & N Afr & B & $<1$ & 6 & Arg379 $\rightarrow$ Gly & Arg379 $\rightarrow$ Gly & $(\mathrm{A} 2 \mathrm{H} 2 \mathrm{~h} 7 \mathrm{I} 2 \mathrm{M} 2) \times 2$ \\
\hline F7-4 & $\mathrm{F}$ & & B & 2 & 62 & $64+5 \mathrm{G} \rightarrow \mathrm{A}$ & Gly $179 \rightarrow$ Arg & A1A1 H1H1 h6h7 I1I1 M1M1 \\
\hline F7-5 & $\mathrm{M}$ & & B & $<1$ & 17 & $3933+1 G \rightarrow A$ & $3762 G \rightarrow A$ & (A1 H1 h6 I1 M1) x2 \\
\hline F7-6 & M & & B & 3 & 23 & Arg304 $\rightarrow$ Gln & Gly $180 \rightarrow$ Arg & $\mathrm{A} 1 \mathrm{~A} 2 \mathrm{H} 1 \mathrm{H} 2 \mathrm{~h} 6 \mathrm{~h} 7 \mathrm{I} 112 \mathrm{M} 1 \mathrm{M} 2$ \\
\hline F7-8 & $\mathrm{M}$ & & B & $2^{a}$ & 15 & 10743 delG & Gly $96 \rightarrow$ Ser & (A1 H1 h6 I1 M1) X2 \\
\hline F7-10 & $\mathrm{F}$ & & B & $2^{a}$ & na & 11125 delC and Ala294 $\rightarrow$ Val & Leu13 $\rightarrow$ GIn & $(\mathrm{A} 1 \mathrm{H} 2 \mathrm{~h} 7 \mathrm{l} 2 \mathrm{M} 2) \times 2$ \\
\hline F7-27 & M & Swiss & B & $2^{\mathrm{a}}$ & na & Arg $277 \rightarrow$ Cys & Arg28 $\rightarrow$ Gly & $\mathrm{A} 1 \mathrm{~A} 2 \mathrm{H} 1 \mathrm{H} 2 \mathrm{~h} 7 \mathrm{~h} 7 \mathrm{I} / 2 \mathrm{M} 1 \mathrm{M} 2$ \\
\hline F7-42 & $\mathrm{F}$ & & B & $5^{a}$ & na & Met298 $\rightarrow \| l e$ & Trp364 $\rightarrow$ Stop & (A1 H1 h6 I1 M1) X2 \\
\hline F7-19 & $\mathrm{F}$ & & B & 2 & na & Met1 $\rightarrow$ Val & wt & A1A1 H1H2 h6h7 I1I2 M1M2 \\
\hline F7-13 & $\mathrm{F}$ & & C & 2 & 7 & $6070+1 \mathrm{G} \rightarrow \mathrm{A}$ & Cys135 $\rightarrow$ Arg & $(\mathrm{A} 1 \mathrm{H} 1 \mathrm{~h} 6 \mathrm{I1} \mathrm{M} 1) \times 2$ \\
\hline F7-20 & $\mathrm{F}$ & & C & $<1$ & 25 & $5886+5 G \rightarrow A$ & Glu16 $\rightarrow$ Lys & A1A2 H1H1 h6h7 I1I1 M1M1 \\
\hline F7-26 & $\mathrm{F}$ & & C & $<1$ & 2 & Asn $57 \rightarrow \| l e$ & Asn57 $\rightarrow \| l e$ & (A1 H1 h6 I1 M1) x2 \\
\hline F7-30 & $\mathrm{F}$ & & C & $<1$ & 65 & Phe328 $\rightarrow$ Ser & Asp343 $\rightarrow$ Asn & (A1 H1 h6 I1 M1) X2 \\
\hline
\end{tabular}

The FVIIc column corresponds to the FVII coagulant activity levels. The recombinant human TF (Instrumentation laboratory, Lexington, USA) was used for the coagulant assays except for the samples denoted with a superior $\left(^{\mathrm{a}}\right)$, which were tested with Thromboplastins from human or rabbit origins. The corresponding FVII haplotype is associated with each mutation when possible. A1: allele 73G, A2: allele 73A, H1: allele His 115 CAC, H2: allele His 115 CAT, h6: allele including $6 \times 37$ bp repeats at IVS7, h7: allele including $7 \times 37$ bp repeats at IVS7, 11: allele 10523G, 12: allele 10523A, M1: allele Arg 353 CGG, M2: allele Gln 353 CAG. ${ }^{10-13}$ The mutations which are not reported in the FVII mutation database 2000, are indicated in bold. The numbering is according to O'Hara et al. ' ' $\mathrm{wt}^{\prime}$ indicates a wild type sequence in the screened area. 'na', data not available. 'N Afr' indicates origins from North Africa.

FVII antigen levels could be determined in 26 patients (Table 1). Four patients were classified as 'cross-reacting material negative' $(\mathrm{CRM}-)$ as they had very low or absent antigen levels ( $2 \%$ or less). Seventeen patients had reduced antigen levels $\left(\mathrm{CRM}^{\text {red }}\right)$. Five patients displayed normal antigen levels $(>60 \%)(\mathrm{CRM}+)$, maybe due to the presence in the plasma of functionally altered FVII molecules. ${ }^{2}$ As can be seen in Table 1, none of these antigen-groups was related to the clinical distribution. For example, the clinically severely affected patient F7-30 had normal FVII antigen levels (65\%) whereas an asymptomatic subject, F7-15, can have very low FVII antigen levels $(<2 \%)$.

\section{FVII mutations screening}

DGGE analysis allowed us to characterise 46 out of 74 mutated alleles. Figure 1A,B shows typical electrophoretic patterns of different mutations within exons 5 and $8 \mathrm{~B}$ respectively. All the PCR products displaying an abnormal DGGE pattern revealed a sequence alteration. The other exons were explored by direct sequencing and showed 22 additional gene defects. After this first screening-step, one or two mutations were still missing in five patients (F7-15, F717, F7-19, F7-31 and F7-37). Direct sequencing of the 5'FR did not allow the detection of another sequence alteration. We then re-examined the three exons previously explored by 
Table 2 Oligonucleotides used to amplify FVII exons, PCR and denaturing gradient gel electrophoresis conditions

\begin{tabular}{|c|c|c|c|c|c|}
\hline Exon & $5^{\prime}$ oligomer $\left(5^{\prime}-3^{\prime}\right.$ sequence $)$ & $3^{\prime}$ oligomer $\left(5^{\prime}-3^{\prime}\right.$ sequence $)$ & Product size (bp) & $A T\left({ }^{\circ} \mathrm{C}\right)$ & DGGE running time \\
\hline $5 F R$ & tatttacatccacacccaag & tgcctgttgacattccccat & 400 & 56 & \\
\hline $1 \mathrm{a}$ & ccatccetctgtcaccettg & atttgcccactgccettcca & 210 & 58 & \\
\hline $1 \mathrm{~b}$ & a agtagggggtgtggcgtgag & tgggaggggaaggaggtgat & 289 & 64 & $5 \mathrm{~h}$ \\
\hline 2 & aggatgggcgaacggggtgg & ccgcagccaaagagacgcag & 444 & 60 & \\
\hline 3 and 4 & cgttgggtgctctggtgaag & ccctgatgeccggcctaca & 386 & 62 & \\
\hline 5 & a agacaccactgctgaccca & tcccaccogtcttttgtcca & 323 & 60 & $6 \mathrm{~h} 30 \mathrm{~min}^{\mathrm{b}}$ \\
\hline 6 & cctgccttccaccaccectg & gctgacctgcccattttccect & 369 & 66 & \\
\hline 7 & gagggcgagtcatcagagaa & tgagacacttgagagctgcg & 421 & 62 & \\
\hline $8 \mathrm{~A}$ & gtgaggtggcaggtggtgga & cgttcgggcaggcagagggga $^{a}$ & 222 & 64 & $4 \mathrm{~h}^{\mathrm{b}}$ \\
\hline $8 \mathrm{~B}$ & acaccaccaaccacgacatc & ccttgctgccatccgagtag & 303 & 62 & $10 \mathrm{~h}$ \\
\hline $8 C$ & agcagcagtcacggaaggtgg & tgccetcctctaccccatta & 391 & 60 & $11 \mathrm{~h}$ \\
\hline
\end{tabular}

A typical $100 \mu \mathrm{l}$ PCR reaction contained, $1 \mu \mathrm{g}$ genomic DNA, 20 pmol of each oligonucleotide primer, $200 \mu \mathrm{M}$ of each desoxynucleotide triphosphate (Pharmacia, Uppsala, Sweden), 1.5 units of Taq DNA polymerase and its buffer (Ampli TaqR, Perkin-Elmer Cetus, Norwalk, CT, USA). For the PCR reactions of both exons $1 \mathrm{~b}$ and 7 , the buffer was replaced by a mix containing $16.6 \mathrm{~mm}$ ammonium sulphate, $67 \mathrm{~mm}$ Tris$\mathrm{Hcl} \mathrm{pH} \mathrm{8.8,} 6.7 \mathrm{mM}$ magnesium chloride, $67 \mu \mathrm{M} \mathrm{Na}{ }_{2}$ EDTA, $170 \mu \mathrm{g}$ bovine serum albumin per $\mathrm{ml}$ and 10 mM $\beta$-mercaptoethanol. ${ }^{2}$ Indicates the primer-end with the additional GC clamp (cgcccgccgcgecccgcgeccgtcccgccgcceccgcccc). AT: annealing temperature. ${ }^{\mathrm{b}}$ Indicates that a $1 \mathrm{~h}$-run prior to loading was applied.

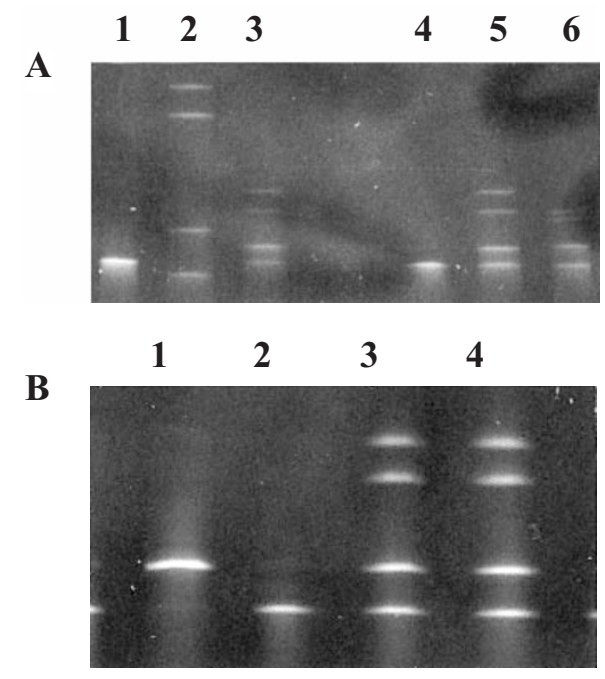

Figure 1 Denaturing gradient gel electrophoresis patterns of FVII mutations. (A) exon 5 DGGE pattern. Lane 1: Normal pattern (patient F7-34), lane 2: heterozygote for two mutations (Gln100 $\rightarrow$ Arg and Gly97 $\rightarrow$ Cys) and for the 115 His dimorphism (patient F7-2), lane 3: heterozygote for the 115His dimorphism (patient F7-27), lane 4: normal pattern (patient F7-33), lane 5: heterozygote for the $115 \mathrm{His}$ dimorphism (patient F7-32), lane 6: heterozygote for the Cys102 $\rightarrow$ Tyr mutation (patient F7-31). (B) exon 8B DGGE pattern. Lane 1: homozygote for the Arg304 $\rightarrow$ Gln mutation (patient F7-22), lane 2: normal control, lanes 3 and 4: heterozygotes for the Arg304 $\rightarrow$ Gln mutation (patients F7-24 and F7-34 respectively).

DGGE for these patients. However, direct sequencing of exons $1 \mathrm{~b}, 5$ and 8 failed to detect any sequence alteration.

\section{FVII mutation spectrum of 37 unrelated patients with severe inherited FVII deficiency} Among the 68 identified mutated alleles, 40 different potential gene defects were detected. Twenty-two out of these 40 sequence alterations were mutations already described, while 18 had not been previously reported ${ }^{1,4,6}$ (Table 1 ). More than a half of these sequence abnormalities (23/40) were located within both exons 2 and 8, whereas no mutation was found in exons $1 \mathrm{~b}$ and 3 . Only two mutations, affecting residues Cys and Arg at positions 135 and 152 respectively, were detected in exon 6 (Figure 2 ). The overwhelming majority of the identified lesions, except a short 15 base-pairs deletion, were single base substitutions.

Genotype distribution of FVII gene mutations (Table 1) Twenty-five out of 37 patients were compound heterozygous for two FVII mutations, whereas 11 were found to be homozygotes. One patient still has an undetermined genotype. Among the 11 homozygous patients, six had a known family history of consanguinity (patients F7-1, -12, $-14,-16,-23,-38)$. A seventh patient (F7-22) is also probably homozygous for the Arg304 $\rightarrow$ Gln, a relatively frequent missense mutation. His parents could bear the same $\operatorname{Arg} 304 \rightarrow$ Gln missense mutation at the heterozygous state by accident. As the parents' data were not available, the remaining four homozygous patients (F7-9, -25, -26, -40) can be either real homozygotes or compound heterozygotes for the identified mutation and a large deletion on the other allele. F7-10, F7-32 and F7-41 patients showed an unusual genotype including three different mutations (Table 1). The 11125 delC frameshift mutation has been shown to be frequently associated in cis with the Ala294 $\rightarrow$ Val missense mutation in the Polish. ${ }^{5}$ The DNA from these patient's families was not available to further characterise their genotype. However, we can assume that both $11125 \mathrm{delC}$ and Ala294 $\rightarrow$ Val mutations probably lie on the same chromosome in these patients, whereas the third mutation represented the second mutated allele. 


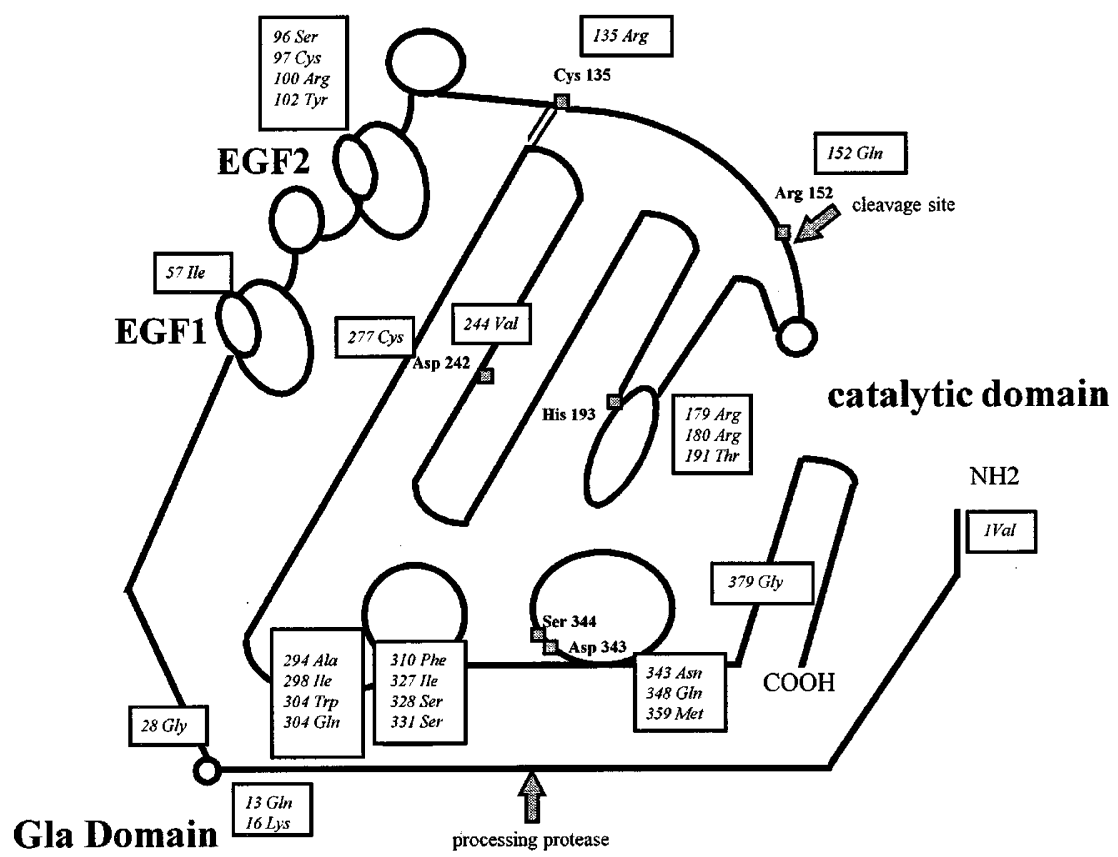

B



Figure 2 Mapping of the 40 FVII mutations that were identified in this study. (A) Mapping of the FVII missense mutations on the FVII molecule. The $28 \mathrm{FVII}$ missense mutations are noted in italics. Critical residues of the FVII activation pathway and the typical residues of the catalytic triad are noted in bold type. (B) Location from the $5^{\prime}$ to the $3^{\prime}$ end of the FVII gene of the 40 different sequence alterations.

\section{Polymorphisms and haplotypes associated with FVII} mutations

The extensive analysis of the coding region and splice sites of FVII gene allowed us to detect eight sequence variations with apparently no disease causative effect. Six were already published common polymorphisms ${ }^{10-13}$ whereas two were still undescribed. A Gln35 dimorphism was characterised in exon 2 at the heterozygous state in patient F7-33 and at the homozygous state in patient F7-40. Both patients F7-33 and F7-40 shared the same Cys310 $\rightarrow$ Phe missense mutation. A C to T substitution at nucleotide 3954 in intron 2 was identified once at the homozygous state in patient F7-23 who is of Asian origins. This polymorphism has not been found in a 50 chromosomes control group. The most common polymorphisms were used to construct FVII haplotypes associated with each mutation when possible (Table 1).

\section{Discussion}

We have screened for mutations the entire coding regions and boundaries of FVII gene in 37 unrelated patients with inherited FVII deficiency. Among the 74 predicted FVII mutated alleles, 68 were characterised and corresponded to 32 complete FVII genotypes.

\section{Strategy for the identification of FVII mutations}

DGGE was chosen as the first screening step because of its reliability and of the large number of patients who can be simultaneously investigated. No mutation evaded detection in our study as far as we could check. DGGE could not be applied to the entire coding sequence because the base composition of FVII gene is GC rich with a $60 \% \mathrm{G}+\mathrm{C}$ content. ${ }^{7}$ This characteristic is common to other vitamin $\mathrm{K}$ dependent factors such as factor $\mathrm{X}$ or Protein $C .^{7}$ This explains why gradients with high percentages of denaturant as well as long running times were necessary to accurately identify FVII mutations using DGGE. However, DGGE screening allowed the detection of 46 out of the 68 FVII mutated alleles (68\%), corresponding to the complete genotypes of one third of the patients (13/37). DGGE is useful when studying large series of patients and should be first applied for the frequently mutated exons 8 and 5 . 
Furthermore, DGGE can be also performed as an individual screening tool, using a sequential loading on the same running gel.

\section{FVII gene mutations spectrum in FVII deficiency}

The overwhelming majority of the FVII mutations are single nucleotide variations according to the literature data. Short deletions (2-30 nucleotides) are rare on FVII gene. One was identified in this study, and another has been previously described. ${ }^{1,14}$ Both are closely located, at the beginning of exon 8 which is a known region for nucleotide sequence repetitions. The single point mutations are distributed throughout the FVII gene suggesting that almost every domain of the molecule is essential for maintaining its overall structure and specific function. Only six gene defects could not be detected, despite an extensive screening. These missing mutations might occur within unexplored intronic regions and activate a competitive cryptic splice site. Further studies on illegitimate RNA transcripts would be useful to characterise the genetic mechanisms underlying the FVII deficiency, for these patients. Another possibility might be the existence of a large deletion or a gross gene rearrangement which would evade detection by DGGE or direct sequencing. Finally, the modification of an alternative locus which may control FVII levels has been suggested. ${ }^{15}$

\section{Phenotype to genotype relationship in clinically severe FVII deficiency}

Both FVII clotting activity and FVII antigen are known to be poorly correlated to the bleeding tendency in inherited FVII deficiency. ${ }^{16}$ On the other hand, in many reports, severe mutations preventing synthesis of any amount of FVII protein have been shown to be associated with lifethreatening haemorrhages. ${ }^{16-18}$ This is in agreement with FVII gene knock out experiments in mice. These mice frequently die during the first day after birth because of fatal haemorrhages. ${ }^{19}$ In our study, most of the genotypes of patients with severe bleeding diathesis, appeared to comprise on both alleles mutations preventing the production of a functional FVII molecule. Actually, in the clinically severe group C, 15 out of the 16 mutated allele can be considered as deleterious mutations on the basis of different mechanisms.

\begin{abstract}
Alteration of the FVII activation pathway Three previously described missense mutations and one novel sequence-alteration occurred at residues implicated in the activation pathway of FVII. The Arg $152 \rightarrow$ Gln occurs at the site that must be cleaved to generate activated FVII. ${ }^{20}$ The rate of the 328Ser mutant activation by activated factor $\mathrm{X}$ was shown to be markedly reduced. ${ }^{21}$ The $135 \mathrm{Arg}$ mutant ${ }^{4}$ destroys the unique disulphide bridge, connecting the light and heavy chains of activated FVII. The novel Asp343 $\rightarrow$ Asn mutation, involves a critical and highly conserved residue. After proteolytic activation of the factor VII zymogen, the $\beta$ -
\end{abstract}

carboxyl group of asparatic acid residue 343, adjacent to the active serine residue 344 , forms the trypsin typical salt bridge with the newly exposed NH2-terminal alpha amino group of Ile 153. This salt bridge stabilises the active conformational state of the serine protease domain. ${ }^{22}$ Thus, the residue Asp343 appears to be essential for the catalytic activity of the complex FVIIa/TF.

Secretion defect Both previously described 359Met and $348 \mathrm{Gln}$ mutants are sequestered in the protein secretory pathway. ${ }^{23-24}$ In the same way, the FVII Arg100 mutant displays an abnormal conformation leading to a major, secretion defect. $^{25}$ The novel Asn57 $\rightarrow$ Ile mutation lies within the N-terminal EGF like domain at an evolutionary conserved residue. A Asn57 $\rightarrow$ Asp mutant has been reported by Leonard et al. ${ }^{26}$ Because of the loss of an important intra-molecular hydrogen bond between Asn57 and Cys81, these mutations could alter the folding of the first EGF domain. In the Asn57 $\rightarrow$ Asp model, this substitution resulted in a marked decrease in FVII mutant protein secretion with the loss of both procoagulant activity and TF binding. ${ }^{26}$

Generation of a truncated or elongated protein The frameshift 11125delC mutation has been reported at the homozygous state, in cis with the Ala294 $\rightarrow$ Val substitution, in several subjects with moderately severe to severe bleeding diathesis. ${ }^{5}$ The $6070+1 \mathrm{G} \rightarrow \mathrm{A}$ transition occurs at the invariable dinucleotide splice site of intron $4 .{ }^{17}$ Concurrently the newly described substitution of a $\mathrm{C}$ by a $\mathrm{T}$ at position 5965 generates a premature termination codon TAG at position 49 in the first EGF domain. The truncation of the EGF2 and catalytic domains, even if some amount of the mutant protein is still translated, would lead to an inactive polypeptide. The $5886+5 \mathrm{G} \rightarrow \mathrm{A}$ transition occurred at the nucleotide position +5 at the $5^{\prime}$ splice site of intron 3 . The frequency of a $\mathrm{G}$ at position +5 of the consensus splice site scored 0.84 whereas an $\mathrm{A}$ at the same position scored $0.05{ }^{27}$ As an $A$ is extremely rare at this position, the $G$ to $A$ transition may lead to the skipping of the corresponding exon or the activation of a cryptic splice site in the vicinity. A similar mutation in the FVII intron $7(9726+5 \mathrm{G} \rightarrow \mathrm{A})$ has been found to disrupt the usual $5^{\prime}$ donor splice site. ${ }^{28}$

Expression defect Two mutations have been shown to alter FVII expression in vitro. Both $-61 \mathrm{~T} \rightarrow \mathrm{G}$ and $-55 \mathrm{C} \rightarrow \mathrm{T}$ mutations occurred at the binding site of the transcription factor: hepatic nuclear factor 4 (HNF4). ${ }^{29}$ The $-61 \mathrm{~T} \rightarrow \mathrm{G}$ mutation completely abrogated gene expression in reporter gene assays, ${ }^{18}$ whereas the $-55 \mathrm{C} \rightarrow \mathrm{T}$ mutation exhibited only $10 \%$ of expression level in vitro. ${ }^{30}$

Finally, the sixteenth Glu16 $\rightarrow$ Lys mutated allele associated with a clinically severe phenotype, has an hypothetical severity. This mutation has a FIX counterpart (Glu17 $\rightarrow$ Lys) causing severe haemophilia $\mathrm{B},{ }^{31}$ but the phenotypic con- 
sequences of the FVII 16Lys variant have to be further explored.

Thus in the severe group, both mutated alleles of eight out of nine patients could be related to severe FVII mutations, suggesting that the severe phenotypes could be related to the total absence of FVIIa. Conversely, this is not the rule in both mild or asymptomatic groups. In these groups, one severe mutation can be found occasionally but not on both alleles. In these cases, the other allele, that we could call 'mild', may allow the release of a minute amount of FVII protein that could be sufficient to trigger the haemostatic cascade. Conventional clotting assays may not be sensitive enough to detect the residual FVII activity. Whether a small release of FVII could be sufficient to prevent the expression of severe phenotypes needs further analyses. FVII variants from both A and B groups are currently under investigation to throw light on the structure-function relationships of FVII and on new prognostic parameters for bleeding tendency in severe inherited FVII deficiency.

\section{Acknowledgements}

The authors are grateful to Pr Thierry Maudelonde and Dr Jean-Marc Rey for technical help in sequence analysis. The authors wish to also acknowledge Dr Mike Morris and Pr Philippe de Moerloose for review of the manuscript. This work was supported by the programme Hospitalier de Recherche Clinique 1997, CHU Montpellier.

\section{References}

1 Cooper DN, Millar DS, Wacey A, Banner DW, Tuddenham EGD Inherited factor VII deficiency: molecular genetics and pathophysiology. Thromb Haemost 1997; 78: 151-160.

2 Triplett DA, Brandt JT, McGann Batard MA, Schaeffer Dixon JL, Fair DS: Hereditary Factor VII deficiency: heterogeneity defined by combined functional and immunochemical analysis. Blood 1985; 66: $1284-1287$.

3 Peyvandi F, Mannucci PM, Asti D, Abdoullahi M, Di Rocco N, Sharifian R: Clinical manifestations in 28 Italian and Iranian patients with severe factor VII deficiency. Haemophilia 1997; 3: $242-246$.

4 Wulff K, Herrmann FH: Twenty two novel mutations of factor VII gene in Factor VII deficiency. Hum Mutat 2000; 15: 489-496.

5 Arbini AA, Bodkin D, Lopaciuk S, Bauer KA: Molecular analysis of Polish patients with factor VII deficiency. Blood 1994; 84: $2214-2220$.

6 Peyvandi F, Jenkins PV, Mannucci PM et al: Molecular characterisation and three-dimensional structural analysis of mutations in 21 unrelated families with inherited factor VII deficiency. Thromb Haemost 2000; 84: 250-257.

7 O'Hara PJ, Grant FJ, Haldeman BA et al: Nucleotide sequence of the gene coding for human factor VII, a vitamin K-dependent protein participating in blood coagulation. Proc Natl Acad Sci USA 1987; 84: 5158-5162.

8 Abrams ES, Murdaugh SE, Lerman LS: Comprehensive detection of single base changes in human genomic DNA using denaturing gradient gel electrophoresis and a GC clamp. Genomics 1990 7: $463-475$.

9 Biron C, Lamarti H, Schved JF et al: Diagnosis strategies in activated protein $C$ resistance: is genotyping still necessary? Clin Lab Haem 1997; 19: 67-71.
10 Marchetti G, Ferrati M, Patracchini P, Redaelli R, Bernardi F: A missense mutation (178Cys $\rightarrow$ Tyr) and two neutral dimorphisms $\left({ }^{115} \mathrm{His}\right.$ and $\left.{ }^{333} \mathrm{Ser}\right)$ in the human coagulation factor VII gene. Hum Mol Gen 1993; 2: 1055-1056.

11 Marchetti G, Patracchini P, Gemmati D et al: Detection of two missense mutations and characterization of a repeat polymorphism in the factor VII gene (F7). Hum Genet 1992; 89: 497-502.

12 Green F, Kelleher C, Wilkes H, Temple A, Meade TW, Humphries $\mathrm{S}$ : A common genetic polymorphism associated with lower coagulation factor VII levels in healthy individuals. Arterioscler Thromb Vasc Biol 1991; 11: 540-546.

13 Peyvandi F, Mannucci PM, Bucciarelli P et al: A novel polymorphism in intron 1a of the human factor VII gene (G73A): study of a healthy Italian population and of 190 young survivors of myocardial infarction. Br J Haematol 2000; 108: $247-253$.

14 Bernardi F, Castaman G, Redaelli R et al: Topologically equivalent mutations causing dysfunctional coagulation factors VII $(294 \mathrm{Ala} \rightarrow$ Val) and X (334 Ser $\rightarrow$ Pro). Hum Mol Gen 1994; 3: $1175-1177$

15 Fagan K, Wilkinson I, Allen M, Brownlea S: The coagulation factor VII regulator is located on 8p23.1. Hum Genet 1988; 79: $365-367$.

16 Mariani G, Lo Coco L, Bernardi F, Pinotti M: Molecular and clinical aspects of factor VII deficiency. Blood Coagul Fibrinolysis 1998; 9: S83-S88.

17 McVey JH, Boswell EJ, Takamiya O et al: Exclusion of the first EGF domain of factor VII by a splice site mutation causes lethal factor VII deficiency. Blood 1998; 92: 920 - 926.

18 Arbini AA, Pollak ES, Bayleran JK, High KA, Bauer KA: Severe factor VII deficiency due to a mutation disrupting a hepatocyte nuclear factor 4 binding site in factor VII promoter. Blood 1997; 89: $176-172$

19 Rosen ED, Chan JCY, Idusogie E et al: Mice lacking factor VII develop normally but suffer fatal perinatal bleeding. Nature 1997; 390: 290 - 293

20 Chaing S, Clarke B, Sridhara S et al: Severe factor VII deficiency caused by mutations abolishing the cleavage site for activation and altering binding to tissue factor. Blood 1994; 83: 35243535.

21 Bharadwaj D, Lino M, Kontoyianni M, Smith KJ, Foster DC, Kisiel W: Factor VII central. J Biol Chem 1996; 271: 30685 30691.

22 Higashi S, Matsumoto N, Iwanaga S: Molecular mechanism of tissue factor-mediated acceleration of factor VIIa activity. J Biol Chem 1996; 271: 26569-26574.

23 Arbini AA, Mannucci PM, Bauer KA: A Thr 359 Met mutation in factor VII of a patient with a hereditary deficiency causes defective secretion of the molecule. Blood 1996; 87: 5085 - 5094.

24 Katsumi A, Matsushita T, Yamazaki T, Sugiura I, Kojima T, Saito H: Severe Factor VII deficiency caused by a novel mutation $\mathrm{His}^{348}$ to Gln in the catalytic domain. Thromb Haemost 2000; 83: 239-243.

25 Hunault M, Arbini AA, Carew JA, Peyvandi F, Bauer KA: Characterization of two naturally occuring mutations in the second epidermal growth factor-like domain of factor VII. Blood 1999; 93: $1237-1244$.

26 Leonard BJN, Chen Q, Blajchman MA et al: Factor VII deficiency caused by a structural variant N57D of the first epidermal growth factor domain. Blood 1998; 91: 142-148.

27 Shapiro MB, Senapathy P: RNA splice junctions of different classes of eukaryotes: sequence statistics and functional implications in gene expression. Nucleic Acids Res 1987; 15: 7155 7174

28 Pinotti M, Toso R, Redaelli R, Berrettini M, Marchetti G, Bernardi F: Molecular mechanisms of FVII deficiency: expression of mutations clustered in the IVS7 donor splice site of factor VII gene. Blood 1998; 92: 1646-1651. 
29 Pollak ES, Hung HL, Godin W, Overton GC, High KA: Functional characterization of the human factor VII 5 '-flanking region. $J$ Biol Chem 1996; 271: $1738-1747$.

30 Carew JA, Lopaciuk S, Bauer A: A new promoter mutation in the HNF4 binding region of factor VII gene in a patient with severe factor VII deficiency. Thromb Haemost 1999; suppl: 17 (abstr).
31 Ghanem N, Costes B, Martin J et al: Twenty four novel hemophilia B mutations revealed by rapid scanning of the whole factor IX gene in a French population sample. Eur J Hum Genet 1993; 1: 144-155. 